\title{
A Qualitative Analysis: Mexican University Student Written Advice to Future Students at the Conclusion of a Semester Abroad Experience
}

\author{
Renee Drabier ${ }^{\mathrm{a}^{*}}$, Linda Y. Ramirez ${ }^{\mathrm{b}}$, and Carol P. Fimmen ${ }^{\mathrm{c}}$ \\ ${ }^{a b c}$ Alamo Colleges District, United States \\ *Corresponding author: email: rdrabier@alamo.edu. \\ Address: Alamo Colleges District, 2222 N. Alamo, San Antonio, TX 78215
}

\section{Introduction}

This study is an analysis of student reflective advice written to future semester abroad students based upon their personal experience in a semester study abroad program. In December 2018, 36 Mexican students wrote individual letters during an end-of-term session in which they were asked to reflect upon their semester abroad experience in San Antonio, Texas. The students composed letters to provide advice for the next student cohort based on what they had learned and what they wished someone had told them to help make the most of their experience. The student advice letters were a follow-on to a beginning of the semester activity in which each student wrote a letter to themselves about their expectations of the semester abroad experience. The objective of the letter writing exercise was to encourage reflective thinking about what they had learned and for the students to evaluate how much they changed as a result of the semester abroad study. The December letters were analyzed for types of advice and categorized by topic area for this report using qualitative methodology. The letters were intended to be delivered as written to students in the next Bécalos cohort.

The classroom activities, analysis, and report tasks were each performed by at least two of the following international programs team members at the Alamo Colleges District, Office of International Programs:

- Special Projects Coordinator

- District Executive Director (Retired)

- International Program Assistant, Bécalos Program

\section{About the Bécalos Program}

Based on the May 2013 agreement between President Barack Obama and Mexican President Enrique Peña Nieto, the Colleges District hosts students annually from the SEP-Bécalos-Santander-Universidades scholarship program to boost the number of cross-border exchanges between the two countries (becaseducacion superior 2017). Students from across Mexico travel to San Antonio for a semester of academic courses, leadership seminars, English as a Second Language (ESL) instruction, and cultural activities. Students are selected for the program by their higher education institution in Mexico. The names of the selected students are sent to the Mexico Ministry of Education who then place the students in a higher education institution in the United States based upon the student's program of study. In August 2018, the Office of International Programs was honored to welcome 36 Bécalos students for our fifth-year cohort in this important program. Bécalos students enrich our campus communities and bring insight to lessons, add talent to our classrooms shared with local students, and promote the internationalization of the Colleges District. The Mexico students' dedication to completing out of class assignments and their serious attitude toward doing their best has been an example and a motivator for our local students and faculty. 
The fifth class (2018) of Bécalos students came from 14 different universities across Mexico. These students study science, technology, engineering and math (STEM) fields at their home universities to one day make an impact on the economic development of Mexico. The program also builds bridges between the American and Mexican peoples. For many of these students, studying in San Antonio was their first time flying on an airplane or visiting the United States.

In addition to academic courses, the program is designed to introduce American culture, advance English language training, enhance independent living and study skills, and provide an orientation to campus life (becaseducacion superior 2017). Students learn how to use the VIA Metropolitan transit system, access library resources, learn the history of South Texas, and build leadership skills that will equip them for bright futures. Additionally, Bécalos students learn about their individual communication styles and have the opportunity to create and share their own international aspirations within the semester abroad program.

Housing is provided at apartments at one of the colleges, with host families, or at near-by catholic residence staffed by sisters who work to create a family atmosphere and healthy, lively relationships among students. The catholic residence is a safe environment designed for young women only and the Sisters actively work to promote an understanding of different cultures and religions.

As a part of the Bécalos program, several classroom experiences designed for the students promote reflective thinking about their semester in San Antonio through written letters. Reflective writing at semester's end combined with a letter they each wrote to themselves at the beginning of the semester are used to capture their initial expectations and a basis to compare what they learned by the end of the term. At the end of the semester, students' sealed envelopes were returned to them to read and reflect on how their experiences through their four-month stay in the US. The reflective exercises were concluded by asking each student to write a letter to a student in the next Bécalos cohort to give advice based on what the student learned during his/her time in the program. Ultimately, these letters will be delivered to students in the next Bécalos cohort. In addition, analysis of the letters will be used to make changes or additions to the program to enhance future international student success.

\section{Aims of the Analysis}

The aims of this analysis were to evaluate peer advice to future students in their semester abroad experience, to gain insight into the student's experience, and to evaluate how student advice can be used to improve future student experiences. Advice from the letters will be used to improve future orientation sessions and ongoing support for the next Bécalos cohort as well as other international students. This analysis will add to the body of knowledge concerning semester abroad experiences of Mexican university students visiting the United States and be applicable to help other international students to gain the most from their experiences while away from home.

\section{Review of the Literature}

The literature regarding the United States and study abroad fall into two major categories: 1) United States students studying overseas and 2) foreign students studying in the United States. Much of the literature falls into the study abroad group concerning US domestic students and their experiences overseas. Among the literature regarding US students in study abroad experiences, NAFSA: Association of International Educators (NAFSA) has compiled a report of independent research that measures the impact of study abroad in higher education (www.nafsa.org/policy-andadvocacy/policy-resources/independent-research-measuring-impact-study-abroad). The introduction to the metadata report asserts that "while more research is still needed in this area, researchers who have measured the impact of study abroad and other international learning experiences have found that they have a positive impact on academic, educational, and professional outcome measures" (http://www.nafsa.org/policy-and-advocacy/policyresources/independent-research-measuring-impact-study-abroad, paragraph 1). Outcomes of the studies indicate that 
study abroad improves completion, retention, transfer rates, and grade point averages. Raby, Rhodes, \& Biscarra, (2014) discuss positive outcomes that occur as a result of study abroad due to engagement-enhancing components including shared common experiences and increased student interaction in collaborative activities. Improvement in language learning and development of intercultural competencies through study abroad experiences were reported outcomes in a University of Minnesota-Twin Cities paper (Stebleton et al., 2013). Ammigan and Laws (2018) indicted the more students are involved in the academic and social aspects of college life, the greater they may benefit in terms of learning and social development.

The second major group of literature falls into the category of foreign student experiences while in the United States. Dorsett (2017) wrote on common expectations of international students studying in US universities that closely fit with what we know about our Bécalos students. As with the students we engaged with in this study, he observed that most students were away from home for the first time and faced challenges including how to cope with a new educational environment, culture, and a new language. He noted that these students bring with them a variety of expectations which are both conscious and unconscious assumptions about the cultural and educational experiences in the United States.

Many of the challenges international students face while studying in the US are addressed by Danielle Geary (2016) who explores some challenges and suggests ideas for sparking interaction between foreign students and Americans. She concluded that the most profound insight of her analysis was networking between people and building authentic friendships facilitate positive change for international students, perhaps more than any other factor. In the Bécalos program, building friendship is facilitated through living arrangements, academic classes, social activities, and volunteer opportunities.

Farrelly (2018) surveyed 573 foreign students in five higher education institutions to determine what international students wished they had known before coming to live and learn in Ireland. The paper discussed the types of academic, sociocultural, and practical resources that both welcoming colleges and international students should consider prioritizing before leaving their home country to significantly help the transition from a home to a host country. The top four responses from students in the Ireland survey were knowledge of how to set up a bank account; knowledge about the cost of living; knowledge about getting accommodation; and knowledge about transport. These are each topics that were listed by Bécalos students in this study. Slantcheva-Durst and Knaggs (2017) conducted focus groups with foreign community college students that provided insights into student experiences related to the importance of English language skills upon arrival in the US, the value of on-campus interactions, and level of interest in the students' own culture which were confirmed in findings from this study.

Other literature concerning student challenges in community colleges indicate that foreign students experience acculturative stress and may require more support to be successful than local students in the college environment (Hansen et al. 2018). A recent dissertation study found that student involvement in social experiences, being academically prepared, and familial support all promote student success of foreign community college students (Bennani 2018). These responses are consistent with the student experiences presented in this Colleges/US-based study.

\section{Sample}

The sample for this research project included the entire population of 36 semester abroad students from Mexico higher education institutions who participated in the fall 2018 Bécalos program at the Colleges District. All of the students were younger than 23 years of age and were fairly evenly divided between males and females as shown in Table 1. More than half of the students were in their first year of college, with the majority of the remaining students in their second year of college study. Only three of the 36 students were in their third year of college. 
Table 1: Population demographics and number of students

\begin{tabular}{lc}
\hline Characteristic & Number of Students \\
\hline Gender: & 17 \\
Female & 19 \\
Male & 9 \\
& \\
Age in years: & 27 \\
Less than 20 years & 0 \\
20-23 years & \\
More than 20 years & \\
& \\
Year in college: & 9 \\
First year & 14 \\
Second year & 3 \\
Third year & \\
\hline
\end{tabular}

Table 2 provides the names of the participating Mexico universities and the number of students in the 2018 Bécalos cohort from each institution.

Table 2: List of Mexican universities and number of students

\begin{tabular}{lc}
\hline Name of Participating University & Number of Students \\
\hline Universidad Politécnica de Monclova-Frontera & 2 \\
Universidad Politécnica Metropolitana de Hidalgo & 8 \\
Universidad Politécnica Yucatán & 1 \\
Universidad Tecnológica de Chihuahua & 3 \\
Universidad Tecnológica de Durango BIS & 2 \\
Universidad Tecnológica de Puebla BIS & 2 \\
Universidad Tecnológica de Guaymas & 1 \\
Universidad Tecnológica de La Laguna Durango & 1 \\
Universidad Tecnológica de Laja Bajío & 1 \\
Universidad Tecnológica de La Zona Metropolitana de Valle de México & 5 \\
Universidad Tecnológica de Saltillo & 4 \\
Universidad Tecnológica de San Luis Rio Colorado & 4 \\
Universidad Tecnológica El Retoño & 1 \\
Universidad Tecnológica Gral. Mariano Escobedo & 1 \\
\hline
\end{tabular}

\section{Data Collection Method}

With two weeks remaining in the fall 2018 semester abroad experience, the fifth annual cohort of Bécalos students were asked to write letters of advice to incoming Fall 2019 Bécalos students as had been done with the previous cohorts. The advice letters were written after students had the opportunity to read letters they had written to themselves about their initial expectations and thoughts at the beginning of the semester program that had been prepared and sealed. Reading these letters created an emotional moment for most, as they realized how much they had changed in such a short amount of time (about three months). After allowing the students some time to discuss and 
process their thoughts and feelings, they were asked to write a letter to an imagined student in the next cohort with advice that they themselves would have liked to have received upon arriving in San Antonio.

The students were given no instruction regarding the type of advice to give or in which language to write the letters. While the majority expressed within the letters the importance of practicing their English skills, the letters themselves were written in Spanish, with the exception of one letter written in English. A bi-lingual, native Spanish speaker reviewed the letters to identify and record the advice provided. One letter was collected at the end of the class session from each of the 36 students in the Bécalos program.

\section{Data Analysis}

A fluent native Spanish speaker with experience in international program delivery and who has lived in both Mexico and the United States carefully read each letter in Spanish to gain an overall understanding of advice topics. Subsequently, the letters were translated from Spanish to English and the elements of student advice contained in each letter was recorded in an Excel spreadsheet.

Qualitative methodology was used in the analysis as it is primarily an exploratory research project based upon nonquantitative data. The analysis is based upon qualitative data from non-numeric information obtained from handwritten letters. The initial organization of the raw data used an open coding methodology (Boyatzis 1998) applied to the elements of the non-quantifiable advice elements given in each of the individual letters. Conventional content analysis was used and coding categories were derived directly from the text data. Once the data elements were identified and coded, the primary data was scanned for words and phrases most commonly used by the respondents to place of data elements into broad categories (Creswell 2013). One member of the research team reviewed the qualitative methodology, coding, and categories and verified the data results recorded by a second member of the research team. The data was then summarized quantitatively by counting the number of elements in each category and creating a summary table of all responses. The three major categories created were labelled as: 1) General Lifestyle Choices; 2) Coursework; and 3) Practical Tips.

\section{Findings}

The majority of the students wrote multiple page letters with advice on general lifestyle choices, practical tips, and coursework advice for how to best navigate life during the four months of the semester abroad experience. Many of the students also included their contact information so incoming students receiving their letter could contact them with any doubts, questions, or general comments and other support during their semester abroad.

Two findings were made that align with the aims of the analysis. First, students provided information on their general lifestyle choices that gives insight into their daily and overall abroad experience. The second included practical tips the students identified that would have improved their experience and can be used to improve future students' experiences. The general lifestyle choices advice is addressed in Table 3 with number and percentage of students who offered the advice, and the practical tips and coursework advice are discussed in Table 4 with number and percentage of students who offered the advice. 
Table 3: General lifestyle choices advice with number and percent of students

\begin{tabular}{lcc}
\hline Category Advice & Number of Students & Percent of Total Students \\
\hline General Lifestyle Choices: & 35 & 97.2 \\
Don't Stay in Your Home & 35 & 97.2 \\
Participate in Volunteer $\quad$ Work/ & & \\
Join School Clubs & 30 & 83.3 \\
Explore the City & 28 & 77.8 \\
Make New Friends & 24 & 66.7 \\
Eat More Home Cooked Meals & 18 & 50.0 \\
Get Out of Your Comfort Zone & 18 & 50.0 \\
Learn the Bus Schedule & 10 & 27.8 \\
Have a Map & & \\
\hline
\end{tabular}

The most frequent advice from students in the general lifestyle choices category were Don't Stay in Your Home and Participate in Volunteer Work/Joint School Clubs. Over 97 percent of students highly recommended that the incoming scholars not to spend all their time in their respective residence, but rather to get out and engage in activities. Several students expressed their regret from having stayed home watching television or sleeping on numerous occasions instead of going out and attending the various events going on around them. Following along this line of thought, 50 percent of the students advocated for Get Out of Your Comfort Zone. With many different activities and events being offered, there are opportunities for students to face their fears of new experiences in an unfamiliar culture. Likewise, over 97 percent advised attending social activities and participating in the volunteer opportunities provided by the Alamo District Colleges, as well as joining college clubs. Many stated that volunteer events allowed them to see various aspects of lifestyles of American people. One student wrote, "Take full advantage of all the opportunities that the Alamo Colleges offers you, I recommend you try to attend the volunteer events, the truth is they doing incredible things and you have the opportunity to see new places and have experiences of a lifetime."

Surprisingly, 67.8 percent of the students recommended eating more home cooked meals and advised against eating out too much. This recommendation was made because eating out is more expensive and fast food is often less nutritious. Students who provided this advice were those who resided in the campus apartments or the catholic residence as they had greater access to going out in the city and spending their limited dollars on fast food meals over those staying with host families where meals were most often provided for them family style. Students did provide a warning with the campus apartment eating-in advice, suggesting to only purchase the amount of food they will be able to prepare and eat. Going overboard with groceries sometimes meant that vegetables and other perishable goods expired before they could be used. Another student wrote, "Watch what you buy, especially when buying groceries, don't just buy things to buy them. Take advantage of the Food Bank at the college, you really save a lot of money [as compared to] when you buy groceries." These comments indicate the health consciousness of the Mexican students as well as their attention to financial frugality regarding food. 
Table 4: Practical tips and coursework advice with number and percent of students

\begin{tabular}{lcc}
\hline Category Advice & Number of Students & Percent of Total Students \\
\hline Practical Tips: & 35 & 97.2 \\
Talk to Everyone in Your Class & 21 & 58.3 \\
Manage Your Money & 21 & 58.3 \\
Manage Your Time & 10 & 27.8 \\
Make Time to Talk to Your Family & 26 & 72.2 \\
Gave Personal Contact Information & & \\
Coursework: & 23 & 63.9 \\
Do Your Homework & 15 & 41.7 \\
Practice Your English Skills & & \\
\hline
\end{tabular}

More than half of the students (58.3 percent) advocated for better management of both the student's time and money. In regard to time management, they suggested creating a schedule that included their roommates so they could hold each other accountable for the activities they wanted and needed to attend. It was also advised to establish a routine as quickly as possible so they could become accustomed to the culture and lifestyle changes. Students pointed out that while back home being late to events is not seen as such a bad thing, punctuality here is held at a very high esteem and very important.

When giving advice on financial management, 58.3 percent of students advised downloading the banking application to track their bank funds. The second most frequent advice was to be certain that their bank account was set for direct deposit. Many students had issues or had to wait longer for their program monthly stipends due to not changing their accounts' delivery option from checks to direct deposit, despite having been informed multiple times at the beginning of the program. This financial advice is consistent with the Farrelly (2018) survey most frequent responses regarding financial knowledge regarding bank accounts that students wished they had known at the beginning of their study abroad in Ireland.

About a fourth (27.8 percent) of the students emphasized the importance of keeping in contact with their family back home. They wanted the future students to know that it was okay to miss their family members and that they should lean on one another to get through the difficult moments together. This correlates with the high number of students advising to get along with and talk to everyone in their Bécalos cohort, instead of limiting themselves to their original home university classmates. They also stated that while their fellow classmates should serve as the base for their support system, they should still attempt to branch out and make friends with others outside of the Bécalos group, as this would allow more exposure to the language and culture of San Antonio and the United States and build lasting friendships.

Regarding coursework, 63.9 percent advised doing the assigned homework before going out for fun. One student wrote, "the classes here are different, be prepared to study a lot and try to do your homework as soon as possible, but don't worry, you will learn a lot and they will help with your English and career." Students indicated that even though they understood the curriculum concepts and may have gone over them back home it took them more time to finish the assignments than they originally thought due to being in English and due to unfamiliarity with some technical terminology. This provided incentive for students to attend the optional ESL course that was offered during the semester, which 41.7 percent advised incoming students to do and supports the focus group findings of SlantchevaDurst and Knaggs (2017).

\section{Discussion}


The aims of this study were to gain insight into the Mexican study abroad student's experience, to provide peer advice for future students in their semester abroad semester, and to use student advice to improve future student experiences. The reflective thinking session asked students to take time to think about their study abroad experience and to provide advice based upon their own learning experiences that would benefit future students. The advice offered is the outcome of the students' reflections on their own experience.

The letters written by the Bécalos students demonstrated how important international experience abroad can be in expanding an individual's knowledge of cultural differences in addition to gaining academic and other personal experience. For example, several students wrote about how important being "on time" to class is in the U.S. which is viewed differently than in their Mexico classrooms. They reflected upon their interaction with others during the study abroad semester to examine what they wished they had known at the beginning of the experience and to offer helpful advice to future students. They thought about how their values of experiences of communication, relationships, and knowledge of people and culture different from their home. One student wrote, "Motivate yourself every day that you wake up, don't stay locked up in the place you'll be staying at, get out and explore." Looking back, many students expressed that they wished they had done more activities during their time in the US.

As an example of student reflection regarding the importance of English language skills, one student recommended, "Practice as much as you can your English skills and I'm telling you, it will be hard but try as much as you can." As discussed in the literature review, the level of language skills of incoming foreign students is a critical factor in their study abroad experience. The value of education and hard work was underscored by a student who advised, "Work hard in your classes, you are here to learn and better yourself. Don't let your homework accumulate due to laziness or outings." Our experience with the Bécalos students is that they are very serious about their education and often serve as positive role models in this respect for our local students.

In the practical tips category students shared advice about strategies for sharing their living environment with new people and managing their money. One student wrote, "My lodging assignment was at Tobin [campus housing] and sharing an apartment with three other strangers is difficult at times. Set rules from the start and through any situation respect each other. It helps a lot to have a chart of responsibilities." Regarding managing their money, a number of students provided information about low-cost, restaurant chain stores that they liked and recommended. From their comments, we learned that many students got tired of pizza early in their study abroad experience as the orientation and many of the information sessions provided pizza for the students. Based on the student advice, in the future when events are being held and food choices are being looked at for the students, we will order food from the recommended restaurants (fast food chicken, hamburgers, Mexican food) before going to the pizza option.

Other practical tips advice regarding local transportation included a student's advice, "Uber and Lift can be a bit expensive, so learn to travel by bus and use Google maps or the San Antonio VIA Bus System app so that you don't get lost." Other students advised using Uber and Lyft only as a last resort, because while they are convenient to move around in, they can become very expensive. The Alamo Colleges has negotiated free bus passes for all registered students for the first time this year. Although some routes were time consuming, the bus passes insured that students could travel anywhere in the city without transportation costs.

The most common local transportation problem students encountered was navigating the VIA bus system. Their advice to solve this problem was to download the VIA bus app, which helped with finding the best routes to use and the times that the buses passed. Other students obtained a map of the city and kept it on their person in case they were not able to use their cellphones. All of the students in this cohort had personal smart phones from home. These were important insights that will be incorporated in future orientation sessions.

Students also provided suggestions on different ways to save money during their time in San Antonio such as noting what restaurants provide the best deals for college students, the best days to go grocery shopping at the Colleges' food pantries, which colleges had a the best stock of foods in their student pantry services, and other tips on store deals and sales. A number of students also suggested bringing a large suitcase with the bare minimum of clothing 
with them from home, as they would more than likely be purchasing new items and souvenirs. Some students indicated that the best time to stock up on gifts, especially electronics, was during Thanksgiving weekend when Black Friday and Cyber Monday came around, demonstrating their awareness of these US. Retail business events. One reason given to conserve their funds was so they would be able to go on independent travel. A few students were able to visit California, Chicago, New York, and several cities within Texas during academic breaks, with one student traveling to two different states.

The advice given as a result of thoughtful reflection provided insight into experiences and cultural learning of the Mexican students that was gained as a part of their study abroad experiences in San Antonio. We are confident these are life experiences that will benefit the students throughout their future and provide advice that will help future students and us to better orient and support future cohorts.

\section{Conclusion}

The Bécalos students expressed profound gratitude at being able to participate in the study abroad program. They also extended their thanks to many faculty, staff, students, and other community members for their personalized help and assistance throughout their experiences. The student advice and suggestions will be used to construct a plan in which we will implement changes to the program to provide even better support for our students.

The Bécalos program encourages students to understand and reshape their own identities and beliefs through inclusion of the unexpected, challenging, and simultaneously rewarding intersection of the unknown and the known. The advice provided by these students illustrates the significance of international education with regard to developing individuals who are not merely students, but global citizens with a broad, multicultural focus that leaps beyond tolerance and sensitivity to join with the common, familial aspects of humankind. Using reflective thinking exercises in the classroom can be an important tool to help students become more cognizant of the impact of their study abroad experience and to recognize aspects of their personal experience.

Given the 2018 Presidential election in Mexico and subsequent changes in higher education administration, the future funding by the Mexican government of the Bécalos program is uncertain. The cathartic impact on the lives of students that are given an immersive educational experience in a different country and culture than their home makes this program invaluable to developing global citizens and promoting internationalization. What can we do as educators in higher education institutions to help our international students to gain the most from their experience? We believe that an important key as confirmed by our Bécalos students is to emphasize the importance of daily lifestyle choices that students make while abroad. It is not enough in the first week of orientation to advise students to get out of their residence, to participate in volunteer activities, and to pursue face-to-face opportunities to meet other students outside of class (as opposed to just online). Because students are most often overwhelmed in the first weeks of their abroad experience, lifestyle messages need to be repeated along with other key advice during the first two months of their experience and continuous opportunities to engage the students socially and culturally. We must find ways to convince students to take responsibility for maximizing their own experience in order for them to get the greatest return. Our hope is that giving the next cohort of students these hand written letters from peers will carry the message in a powerful way that will positively influence them and enhance their study abroad experience.

\section{References}

Ammigan, Ravichandran \& Laws, Kaitlyn N. 2018. "Communications Preferences Among International Students: Strategies for Creating Optimal Engagement in Programs andServices", Journal of International Students, 8(3): 1293-1315. 
Bécalos Education $2017 . \quad$ Superior. Communication. Retrieved at: www.becaseducacionsuperior.sep.gob.mx/files/Comunicacion/Convocatorias/2017/Hyperlinks_PDF/Hyperlinks Bécalos-Santander_Universidades-UTR 2017.pdf

Bennani, Wissem Chefai. 2018. Contributors to the Successful Transfer of International Community College Students. Dissertation. San Francisco State University, Proquest Dissertation 10825118.

Boyatzis, Richard E. 1998. Transforming Qualitative Information: Thematic Analysis and Code Development, Thousand Oaks, London, \& New Delhi: SAGE Publications.

Cresswell, John W. (Ed). 2013. Qualitative Inquiry and Research Design: Choosing among Five Approaches. London: Sage.

Dorsett, James. 2017. "High Hopes: International Student Expectations for Studying in the United States". New Directions for Student Services 158(Summer): 9-21.

Farrelly, Tom, and Murphy, Tony.(2018. "Hindsight is 20/20 Vision: What International Students Wished They Had Known Before Coming to Live and Learn in Ireland." Journal of International Students, 8(4): 1848-1864.

Geary, Danielle. 2016. "How Do we Get People to Interact? International Students and the American Experience." Journal of International Students, 6(2): 527-541.

Hanson, Hardaye R.; Shneyderman, Yuliya; McNamara, Gloria S.; Grace, Lisa. 2018. "Assessing Acculturative Stress of International Students at a U.S. Community College", Journal of International Students, 8(1): 215-232.

NAFSA. 2018. "Independent Research Measuring the Impact of Study Abroad". Retrieved at: www.nafsa.org/Policy and Advocacy/Policy Resources/Policy Trends and Data/Independent Research Measuri ng the Impact of Study Abroad/

Raby, Rosalind Latiner, Rhodes, Gary M. \& Biscarra, Albert. 2014. "Community College Study Abroad: Implications for Student Success" Community College Journal of Research and Practice, 38(2-3): 174-183.

Slantcheva-Durst, Snejana \& Knaggs, Christine (2017). "Community College International Students and their Campus Involvement." Community College Journal of Research and Practice, 43(2): 81-93.

Stebleton, Michael J.; Soria, Drista M.; and Cherney, Blythe T. (2013). The High Impact of Education Abroad: College Students' Engagement in International Experiences and the Development of Intercultural Competencies. Frontiers: The Interdisciplinary Journal of Study Abroad, XXII, Winter/Spring: 1-24. 